\title{
Energy Management in Industry: An Enterprise Engineering Approach
}

\author{
Vilson Roiz Gonçalves Rebelo da Silva ${ }^{1 *}$, Eduardo de Freitas Rocha Loures ${ }^{2,3}$, Edson \\ Pinheiro de Lima ${ }^{2,3}$, Sergio Eduardo Gouvêa da Costa 2,3 . \\ ${ }^{1}$ Universidade Federal do Paraná (UFPR), Curitiba, Paraná, Brasil $;{ }^{2}$ Pontifícia Universidade Católica do Paraná \\ (PUC-PR), Curitiba, Paraná, Brasil. ${ }^{3}$ Universidade Tecnológica Federal do Paraná (UTFPR), Curitiba, Paraná \\ Brasil.
}

\begin{abstract}
Companies have needs and experience new opportunities to build their structure and align organizational process to achieve energy management with higher priority facing economic and environmental issues. The objective of this paper is to present the design and modeling of the Energy Management System (EnMS) in energy-intensive industries in an enterprise engineering approach, according to the management discipline called Business Process Management (BPM). The design of the process is based on the ISO 50001 standard and in good practices cited in the scientific literature. The methodology is characterized as basic, experimental, qualitative, and oriented according to the BPM development cycle. The process design created in the "should be" format presents a framework based on the Plan, Do, Check and Act (PDCA) cycle. The process is described in a necessary and sufficient way, arranging activities, actors and roles to establish an energy management process. The key process model of the energy review was developed in the Business Process Model and Notation (BPMN). The design and modeling allows to: analyze the EnMS as a process for understanding the activities; assist decision making; automate processes; enable collaboration; allow alignment of the process with the strategy; support the change and assisting with the evaluation of the organizational potential to implement the EnMS.
\end{abstract}

Keywords: energy management system, energy-intensive industries, enterprise engineering, business process management.

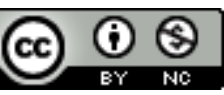

*Author of correspondence: vilroiz@eletrica.ufpr.br 


\section{INTRODUCTION}

The energy issue is nowadays of crucial importance for sustainable economic growth, because it can affect all the society and cause significant impacts on industries. EnergyIntensive Industries (EII) perform an important role in countries development, but unfortunately they also cause environment impacts.

Electric, oil and gas sectors deregulation, obstacles to meeting growing global demand, price volatility, availability of distributed generation application with renewable sources, Smart Grid technology, electric mobility, emission of greenhouse gases and environmental pollution are scenarios that lead to a complexity that requires new approaches and studies for energy management.

The term "Energy Management" may have several meanings in different fields of knowledge. For this research work, EnMS applied in the EII sector, is an interdisciplinary field that can involve engineering, administration, economics, financial, etc. The word energy can be used in several contexts, and in this research it is related to the ability of a system to perform external activity or work.

Energy is also referred to in its various forms, such as electricity, fuel, steam, heat, compressed air and other analogous forms that can be purchased, stored, processed, used in equipment or in a process, or recovered.

The purpose of an Energy Management System (EnMS) is to enable organizations to establish systems and processes necessary to improve energy performance, including energy efficiency, use and consumption.

The scientific literature reports that the term "Energy Efficiency Gap" concerns to broach and discuss the reasons of why energy management projects and investments, even economically and technologically feasible, are not effectively implemented in industries worldwide $\mathbf{1 , 2}, \mathbf{3}$.

Successful EnMS in industries faces problems that are in the form of barriers, which may be originated from: (i) external aspects, such as market, government/politics, suppliers, technology/services, designers, manufacturers, energy suppliers and funders; (ii) intra-organizational, behavioral and organizational aspects.

EnMS research in industries is predominantly focused on system improvements and technological aspects related to energy efficiency, and there is relatively little work on organizational aspects. Recently, the ABNT NBR ISO 50001:2011 - Energy Management Systems ${ }^{4}$ standard was published, which provides guidelines and specifies requirements for the establishment, implementation, maintenance and improvement of an energy management system. Brazil records only 33 companies certified by ISO $50001^{4}$, offering many opportunities to expand the use of this international EnMS standard.

The organizational barriers for EnMS may be better known through the Enterprise Engineering (EE) perspective. The EE is a vast field of multidisciplinary research that approaches new interpretations. Its main concern is the development of methods and tools for the design and implementation of organizational systems, which covers elements such as enterprise architecture, organizational structure, information systems and business processes.

EE provides ways to model and evaluate the dimensions of an organization with the relationships and dependencies between the business processes and management support systems, leading to concerns regarding system integration and interoperability 5.

The main topics that involve organizational engineering are: (i) modeling and integration; (ii) reference models; (iii) business processes; (iv) ontologies; (v) virtual enterprises; (vi) interoperability; (vii) organizational architecture ${ }^{6}$. 
In any type of company, the goal is always to meet the needs of customers and bring profits and dividends to owners and shareholders. Therefore, the set of activities that comprise it should be understood as business processes also called organizational processes. These are characterized as a group of related activities that use human resources, information and any other resources in order to add value for the client. The processes present input and output, beginning and end, time and place, constituting the connection between clients and the organizational structure.

Therefore, business process management is defined as business process support, using methods, techniques and software to design, activate, control and analyze operational processes involving humans, organizations, applications, documents and other sources of information ${ }^{7}$.

According to ${ }^{8}$, process management provides lateral coordination mechanisms, encourages organizational learning, and complements traditional hierarchical training. Considering that the focus is on the processes and not on the functions, a change in the organizational structure from vertical to horizontal is induced, requiring great changes in the corporate structure and management policy ${ }^{9}$.

Figure 1 illustrates the proposition for process management.

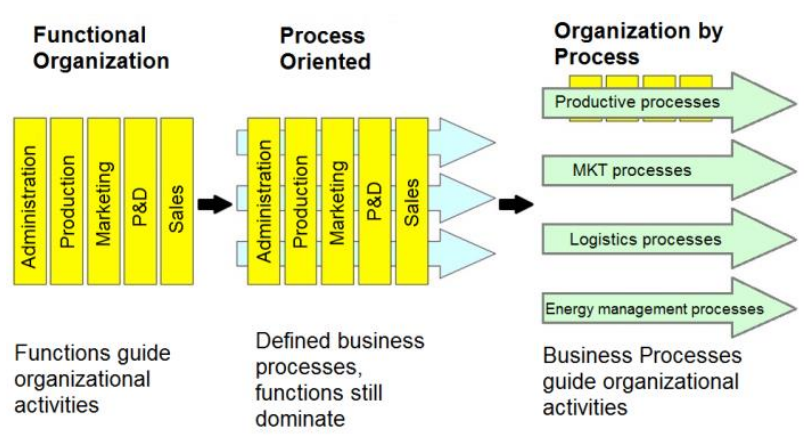

Figure 1- Organizational Structures.

Source: The author.

The use of Business Process Management (BPM) to treat the EnMS with a process vision has the following benefits: (i) a better understanding and transparency of the activities carried out; (ii) clear definition of roles and responsibilities that assist in coordination and decision-making; (iii) enables collaboration and compliance with interoperability requirements; (iv) allows alignment of the process with the strategy; (v)supports change; facilitates the automation of processes; (vi) assists in the evaluation of the organizational potential for the deployment of the EnMS.

\section{METHODOLOGICAL STRUCTURE BASED ON BUSINESS PROCESS MANAGEMENT (BPM)}

The research is characterized as basic, experimental and qualitative, oriented in the light of the BPM development cycles recommended in the literature, in its stages of design and modeling.

The general objective of the paper is to develop a study on energy management in EII under an EE approach. The specific objectives established are: (i) to design an EnMS for EII based on ISO $50001{ }^{4}$ and on best practices cited in the scientific literature, under a the dimension of BPM; (ii) to present a conceptual framework to support the understanding of the process design for an EnMS; (iii) to model the designated Energy Review (ER) process in Business Process Model and Notation (BPMN). 


\section{Problem Structuring}

The scientific literature describes the barriers to effective energy management in industry. In relation to the organizational barriers, different aspects stand out: (i) lack of effective internal management in the company (coordination); (ii) complex chain of decision; (iii) lack of power and influence of the energy manager; (iv) lack of communication between plants; (v) organizational culture leading to neglect of energy and environmental aspects; (vi) little importance of the energy efficiency program (not the main business of the company); (vii) little understanding of how to create support for an energy efficiency project; (viii) organizational inertia to change the current situation; (ix) divergent interests; (x) lack of time; (xi) lack of internal coordination ${ }^{\mathbf{3}, 10}$, $11,12,13,14$

There is also a small study and attention to organizational barriers ${ }^{15,16}$. On the other hand, some proposed models ${ }^{15,16,17,18,19}$ still do not allow us to establish a format that details conditions to assist in solving organizational barriers. This research paper proposes to formulate, under the dimension of BPM, a study on EnMS in the EII to contribute, remove or overcome organizational barriers.

EII are large-scale companies with a key role in the economic and social development of any country. Due to the high energy consumption associated with their processes, EII has a significant impact on the environment, either due to emissions of greenhouse gases, damages caused by raw material extraction or environmental accidents such as soil contamination, surface water and/ or groundwater.

The EII presents great opportunities to reduce the energy spent in the processes, requiring in most cases the analysis of: design (redesign) of the industrial process and its implications; residual heat dissipation into the atmosphere; waste stream.

The EII classification shows small variations according to the country, types of associations of companies and their governmental regulatory organizations.

In this paper, the following industrial segments were considered as EII: (i) petrochemical industry; (ii) cement industry; (iii) pulp and paper industry; (iv) aluminum industry; (v) glass industry; (vi) chemical industry; (vii) iron and steel industry.

\section{The Business Process Management (BPM)}

The BPM life cycle is represented in development phases, and the model established by ${ }^{20}$, proposed in Figure 2, is adopted in this paper. The representation presents, in the first phase, the design, also referred to as conception or definition. The second phase refers to modeling. The third phase is the execution. The fourth phase is the monitoring and the fifth phase is the optimization.

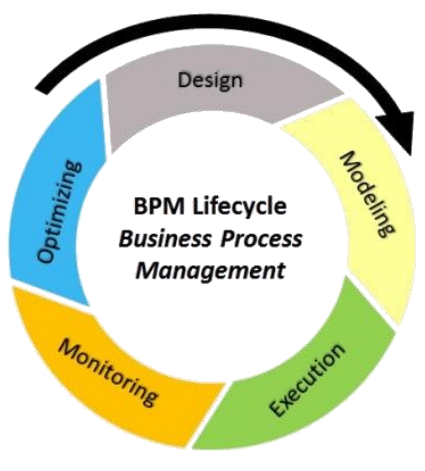

Figure 2 - BPM Lifecycle.

Source: Adapted by the author based on reference ${ }^{\mathbf{2 0}}$. 


\section{Business Process}

Processes consist of a set of activities performed by people and/or machines to achieve results regardless of where activities are performed. In a BPM context, a business process can cross borders to deliver a product. Thus, a process design should consider process-level work and activities that are performed in different functional areas and by multiple people. Thus, "function" refers to groups of specialized activities and competencies related to particular objectives or tasks, and functional areas are represented as departments with vertical orientation of command and control based on specialization ${ }^{20}$.

The hierarchy of processes can be established in the following arrangement: macro process, process, sub-process, activity and task. The task being the smallest working instance of an activity.

The processes can be considered, according to ${ }^{20}$, in three main types: (i) primary processes that are end-to-end processes and typically of a cross-functional nature and make up the chain that delivers value directly to the costumer; (ii) support processes that provide support and make other processes feasible, a process that delivers values to other processes and not directly to customers; (iii) management processes that are used to measure, monitor and control business activities. They do not directly add value for customers, but are necessary to ensure that the organization achieves its goals.

Therefore, the process of an EnMS can be understood as a process supporting the overall management of the organization. It should be noted that for some industrial processes (petroleum) it can also be considered as the primary process.

\section{Process Design}

The process design is the formal definition of objectives and deliverables and the organization of the activities and rules necessary to produce a desired result. The process design aims at defining and designing what the organization, in a tangible and measurable way, will accomplish to achieve its objectives through a new process.

The design of a process is an activity of identification and mapping of the expected results for an operation ${ }^{\mathbf{2 1}}$.

When designing a new process, the following best practices should be taken into account: (i) focusing on activities that add value; (ii) minimizing handoffs (any point in a process in which work or information passes from one function to another is a handoff in that process); (iii) combining similar workflows into a single workflow; (iv) ensuring continuous flow so that nothing will interrupt or delay the value chain; (v) redesigning the process before considering automation; (vi) guaranteeing quality at the beginning of the process to avoid bottlenecks, failures and bad deliveries; (vii) standardizing the processes.

Activities associated with process design include: (i) designing the process with modeling tools and other support tools; (ii) defining the activities for the new process; (iii) defining the rules for the new process; (iv) defining handoffs between functions; (v) defining the measurement; (vi) making comparisons and benchmarking; (vii) conducting simulations and tests; (viii) creating an implementation plan.

\section{Process Modeling}

Process Modeling corresponds to the second stage of the BPM life cycle, where process diagrams are analyzed and flows and steps are reviewed. The model can be defined as a representation of reality, projected for some definite purposes ${ }^{22}$. Business process 
modeling is the set of activities involved in creating representations of existing or proposed business processes. The purposes of modeling are: (i) to document an existing process; (ii) to use as training support; (iii) to evaluate standards and conformities; (iv) to simulate different situations; (v) to identify opportunities for improvement (vi) to design a new process; (vii) to facilitate communication and discussion; (viii) to describe requirements for automation ${ }^{9}$.

\section{Business Process Model and Notation (BPMN)}

A notation can be described as a system with standards and rules in such a way that it is possible to write down and express ideas from a given knowledge domain.

Among the various types of notation for process modeling are: (i) BPMN (Business Process Model and Notation); (ii) EPC (Event-driven Process Chain); (iii) UML (Unified Modeling Language); (iv) Integrated Definition Language (IDEF); (v) Value Stream Mapping. The notation chosen for this paper was BPMN, which is the most common notation for business process modeling.

The BPMN was developed to facilitate the understanding of the internal and external processes of organizations, allowing the communication of the procedures involved in the processes among the organizations, using a standard notation according to the reference ${ }^{23}$.

The elements that make up the notation of business process modeling can be organized into four basic categories: (a) Flow objects, composed of events, activities and decision filters (Gateways); (b) Connection objects, composed of sequential flow, message flow and association; (c) Pools and Lanes; (d) Artifacts, composed of data object, group and annotation. Figure 3 shows only the elements of the notation used in this paper.

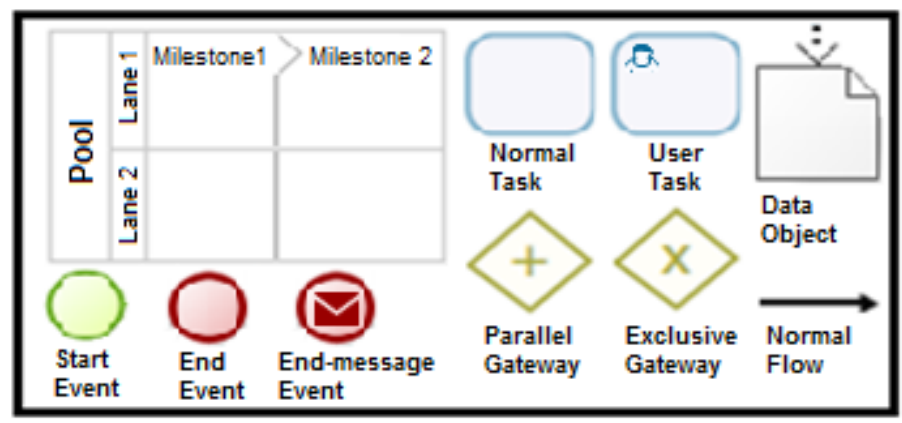

Figure 3 - Notation used in process modeling.

Source: Adapted by the author based on reference ${ }^{24}$.

The following is a brief definition of each element of the notation used:

- Gateway - used to split up or join process flows, allowing process flow sequence control. The markers used in the center of the element indicate different types of behavior. In this paper, we used the Parallel Gateway representing the division of one path into several, and the Exclusive Gateway where, given a conditional, only one path to the flow is chosen.

- Data object - provides information about which activities are to be triggered and/or what they produce.

- Activity - is a work performed within an organization process. It can be classified into atomic or non-atomic (compound) activities.

- Pool - used when the diagram involves two business entities or participants that are physically separated in the diagram, and can be used to represent different processes and organizations. 
- Lane - used to separate associated activities for a specific function or role, thus representing actors and areas of the organization.

\section{Business Process Management Systems/ Suites (BPMS)}

The set of software that automates the BPM (modeling, execution, control and monitoring), is called "BPMS solutions" (Business Process Management Systems/Suites). Large corporations such as IBM, Oracle and Lexmark, for making BPM management operational and automate have developed such tools. Among the several BPMS solutions offered by different developers, we can highlight: (i) Appian v.7.11 (Appian); (ii) AuraPortal Helium (AuraPortal); (iii) Bizagi Studio 10.7 (Bizagi); (iv) IBM Business Process Manager v.8.5.6 (IBM); (v) Oracle Unified Business Process Management Suite 12c (Oracle); (vi) Pega v.7.1.9 (Pegasystems); (vii) Software AG Digital Business Platform BPMS v.9.9 (Software AG).

Figure 4 presents the BPMS selected for the realization of this paper (Bizagi Studio), as well as its development cycle, since it is a free software, friendly interface and widely used by the BPM community. It should be noted that this article only covers the stage of process modeling using the designated part of the software (Bizagi Process Modeler), and it is planned to deploy the other phases in future activities.

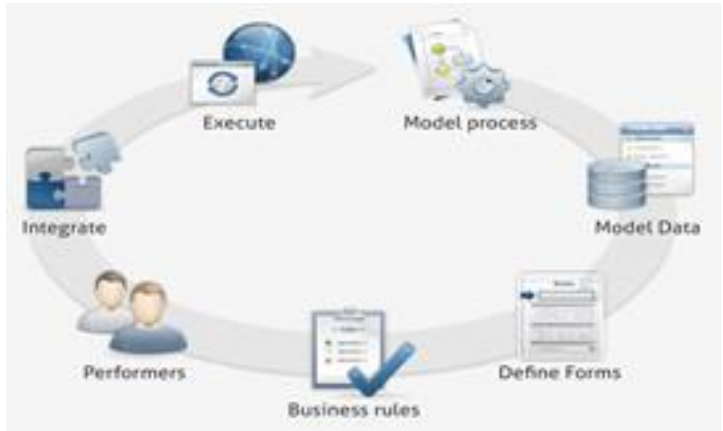

Figure 4 - Bizagi Studio development cycle.

Source: Bizagi ${ }^{24}$.

\section{APPLICATION OF THE METHODOLOGY}

\section{Process Design of an Energy Management System (EnMS)}

The conception of an EnMS in the BPM dimension applied in EIIs, based on ISO 50001 ${ }^{4}$ and on good practices described in the scientific literature, leads to the need to characterize the main actors involved, the internal functional areas and external organizations. The design for the EnMS is set up in the "should be" format because of it being little known in the Brazilian industries and the interest in exploring the expansion of its application, in the face of all the advantages that come up.

\section{Definition of Principal Actors.}

The selected actors were the functional areas that deliver the greatest contribution, have affinity and involvement with the energy management process. They are: (i) Top Management (board of directors selected); (ii) Energy Management Team (EnMT)/Energy Manager, (iii) engineering; (iv) maintenance; (v) production; (vi) 
administration. Also, externally, companies, electric power and gas utility, electric energy trader and Energy Saving Companies (ESCO) were identified.

The so called functional areas of Top Management and EnMT/energy manager are propositions established by ISO 50001 and the functional areas of engineering, maintenance, production and administration are propositions by the author.

The functions of the administration are mainly related to the activities of human resources (personnel, training), purchases (acquisition of energy inputs such as electricity, gas, others), equipment, etc. Also for the administration can be assigned responsibility for general housekeeping services in order to deal with electrical, hydraulic and similar facilities. External organizations and internal functional areas are represented in Figure 5.

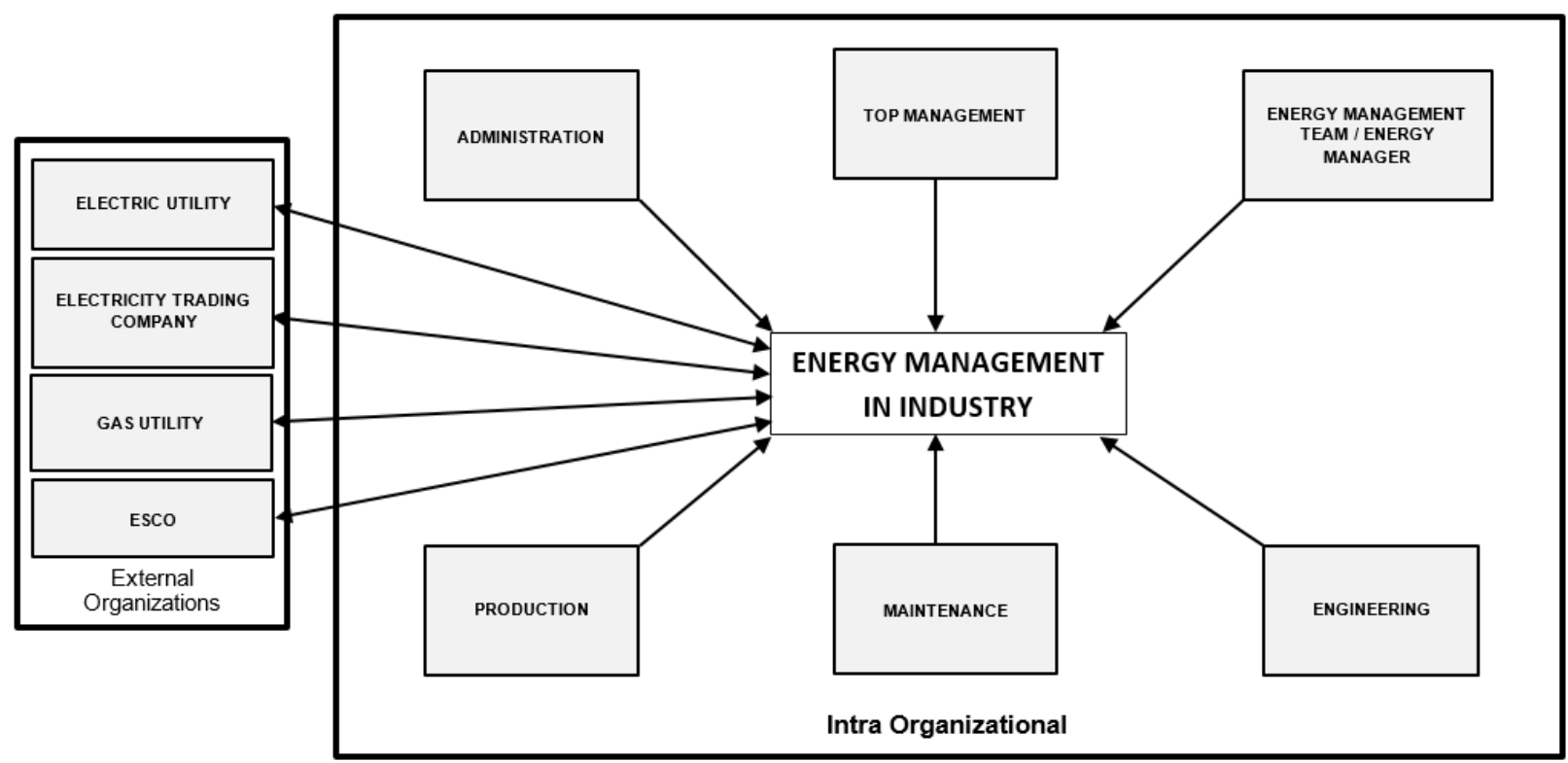

Figure 5- General Representation Diagram of functional areas of a proposed energy management system. Source: The author.

Legal, accounting/financial and marketing functional areas, which due to the complexity of analysis were not considered in this article, could also be considered, to a lesser extent as stakeholders in the EnMS process, but can be studied in future works. Macro process of an energy management system in industry

The Macro Process of an EnMS in EII is shortly described in the form of addressing actions that should be performed to create, organize, and conduct an EnMS.

A board of directors chosen by the organization, linked to the industrial area, defines an energy policy (on behalf of the company) and establishes a strategy for energy management. This board (called Top Management) nominates a representative for the role of energy manager. The energy manager selects employees from across the company to form a multifunctional team ${ }^{25}$. The Top Management approves the constitution of the team.

The EnMT develops a work plan, which, among other activities, verifies compliance with legal requirements ${ }^{26}$ and conducts an initial detailed ER (energy audit style) that could be under the responsibility of the engineering functional area (recommended).

As a result of the ER made by engineering, based on the analysis of electricity and gas significant use and consumption, energy efficiency opportunities, energy baseline, energy performance indicators (EnPI) objectives, energy targets and action plans are set up, duly approved by the Top Management. Subsequently, the implementation stage is carried out in which the equipment and services are designed, acquired and installed to achieve the established targets and objectives. Next, in the verification stage, the 
effectiveness of the plans for the accomplishment of the objectives and targets is evaluated and the actual versus expected energy consumption (and/or other significant variables) is evaluated.

The company performs an internal audit in the EnMS, determining appropriate actions necessary for correcting problems. Finally, Top Management undertakes a critical analysis of the energy performance of the EnMS, addresses nonconformities and disclosures the results to the entire organization.

\section{Conceptual Framework}

The above described actions are represented in: (i) Macro process of a EnMS represented in a horizontal macro flowchart set out in Appendix A and (ii) Conceptual Framework arranged in Figure 6 set in the PDCA cycle (Plan, Do, Check and Act) for better support and understanding of the process design.

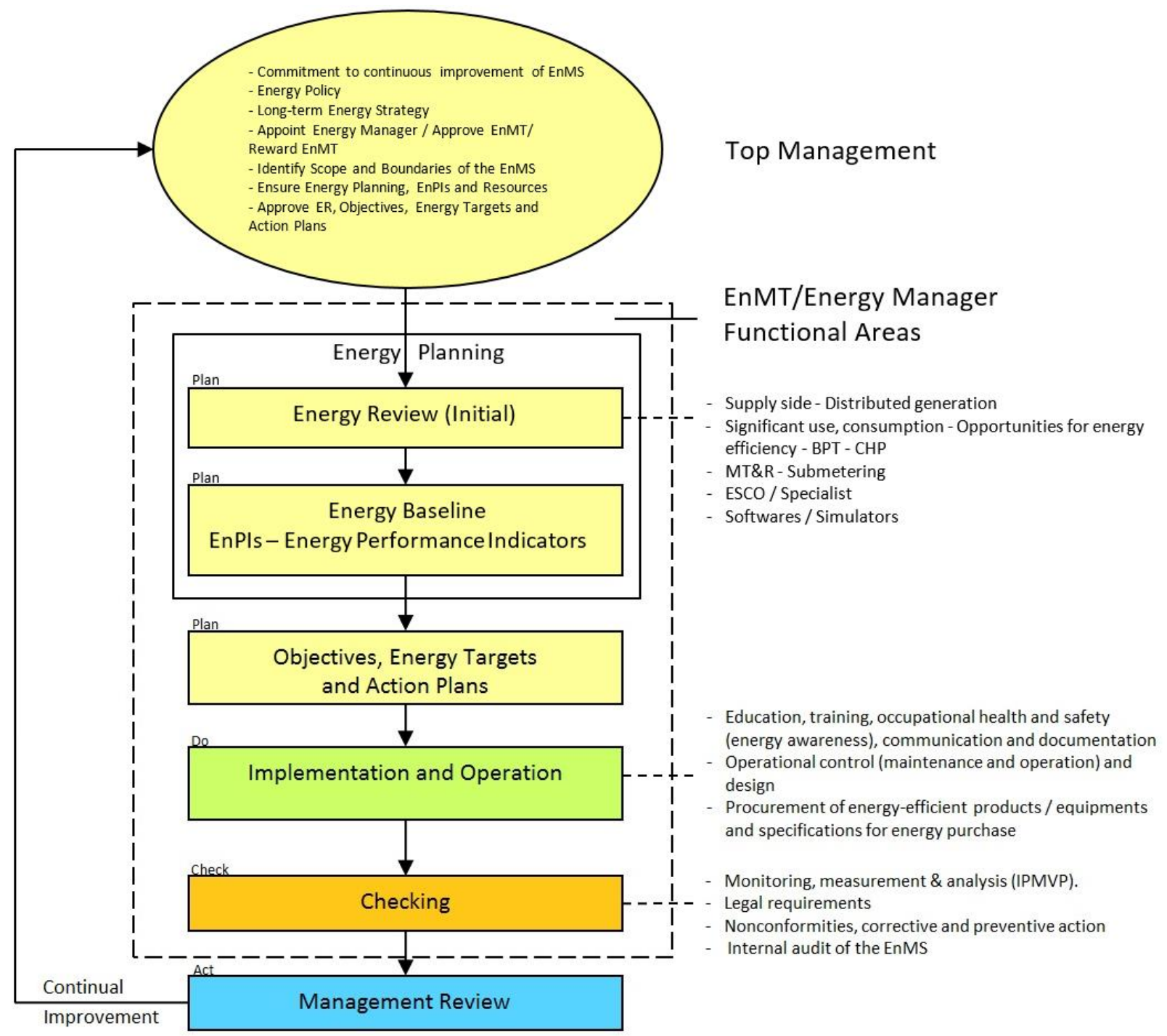

Figure 6 - Conceptual Framework.

Source: Adapted by the author in accordance with reference ${ }^{4}$.

\section{Proposition for a Process of an Energy Management System (EnMS)}

The processes/sub-processes indicated to structure the SGE can be established within the PDCA cycle in the following arrangement: 
- $\quad$ "Plan" - Energy Planning: (i) ER ("key" process); (ii) energy supply; (iii) energy performance indicators (EnPI); (iv) formation of EnMS.

- $\quad$ "Do" - Implementation and Operation: (i) acquisition of energy services, products and equipment; (ii) energy education and training; (iii) documentation (energy manual); (iv) maintenance of the EnMS; (v) invoice control of energy supplies; (vi) acquisition of energy or energy inputs.

- $\quad$ "Check" - Verification of Energy Performance: (i) application of the International Performance Measurement and Verification Protocol (IPMVP) ${ }^{27}$ /or ISO $50015{ }^{28}$; (ii) implementation of the action plans to achieve the objectives and targets; (iii) evaluation of actual energy consumption versus expected; (iv) EnPI verification.

- "Act" - Critical Analysis of the Performance of the EnMS: (i) internal audit of the EnMS; (ii) critical analysis of the EnMS.

The examples and suggestions for the above processes/sub-processes may vary depending on the type of organization, its organizational chart, functional areas and industry type. In this situation, there may also be the transformation of the proposed processes into sub-processes and reciprocally, depending on the functional areas involved.

\section{Modeling of the Energy Review (ER) Process}

Due to the complexity and difficulty in modeling all the processes involved in the SGE, the key processes, and most importantly, the Energy Review, were selected in this work. ER is the determination of the organization's energy performance, based on data and other information, leading to identification of opportunities for improvement. This is also described, in some situations, as energy audit or energy diagnosis.

The initial ER is characterized, in the understanding of this work, as a situation of "evaluation of the current situation" with determination of important and decisive technical and managerial actions (to some extent) for the creation, organization and conduction of a process of energy management in the industry, under the dimension of business process management or BPM.

\section{Mapping and description of the Energy Review (ER) process}

Step 1 - The EnMT requests the engineering area to carry out an initial ER, an activity that constitutes a pillar for energy planning and a key process for GE.

Step 2 - Engineering checks the need of hiring ESCO or specialists to support ER activities. In the contracting condition of ESCO, engineering defines the activities to be performed by this external organization.

Step 3 - Engineering evaluates: (i) supply of electric energy, gas and other relevant energy input; (ii) the feasibility of using distributed generation in its various possibilities (photovoltaic generation, wind, biomass, etc.); (iii) the feasibility of using cogeneration (simultaneous generation of two forms of energy).

Step 4 - Engineering checks: (i) availability of Electronic Monitoring and Measurement Energy System (EMMES)/or Monitoring, Targeting and Reporting (MT\&R) and Submetering; (ii) significant use and consumption of electricity, gas and other fuels; (iii) availability of software/simulators.

Step 5 - Identification of the use, consumption and opportunities for energy efficiency. The engineering consults the functional areas of maintenance and production and receives reports with: (i) indicators of equipment defects (end of life), (ii) legal documentation (electrical installations) and (iii) the opportunity to optimize industrial processes in the production area. Engineering synthesizes data through appropriate software and establishes energy baseline and EnPI. 
Step 6 - Engineering defines the objectives, energy targets, action plans according to the synthesized data and the established energy baseline and EnPI.

Step 7 - The objectives, targets and action plans are forwarded to the EnMS, which, after analysis, send them for the Top Management's approval. Otherwise, the Top Management returns the material to the engineering area for reanalysis. Once approved, the Top Management disclosures to the entire organization and passes on to EnMT to implement the objectives, targets and action plans.

\section{Supplier, Input, Process, Output, Customer (SIPOC)}

The representation of the elements that make up the Supplier, Input, Process, Output, Customer (SIPOC) diagram are presented in the ER process scope in Figure 7. They are detailed with name and owner of the process; mission; actors involved; laws and regulations; indicators; supplier, input, process, output and customer.

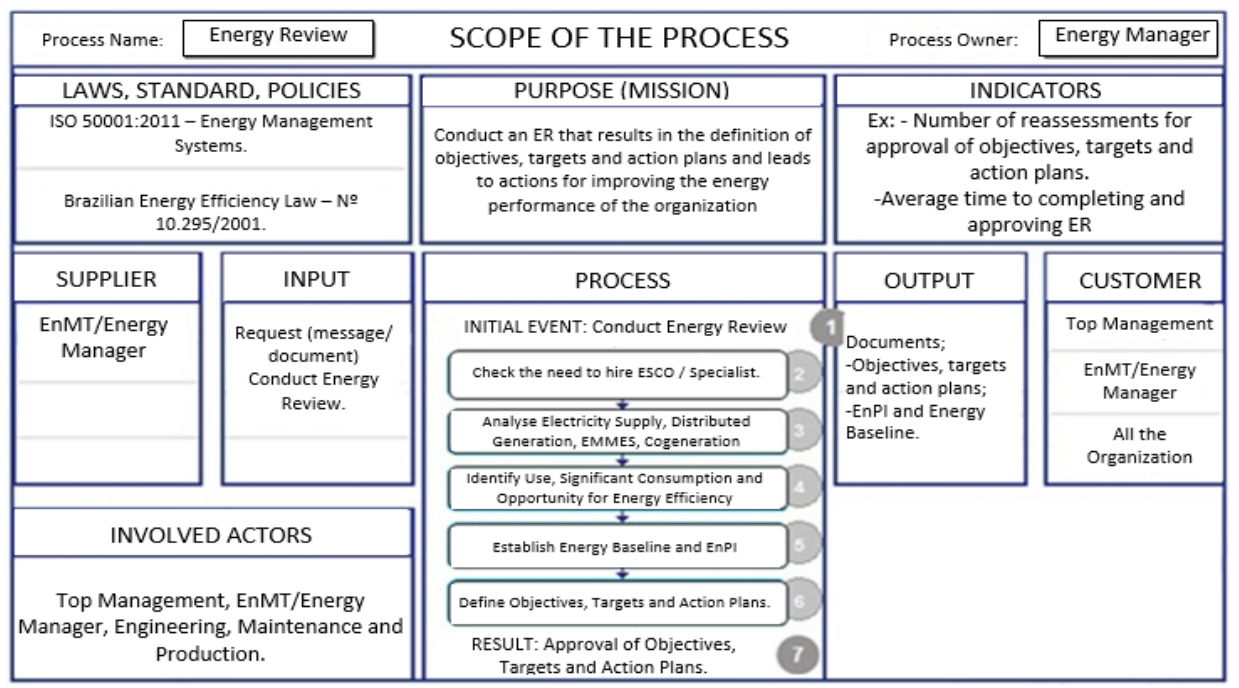

Figure 7- SIPOC Tool Diagram.

Source: The author.

\section{Modeling of the Energy Review process in BPMN}

The modeling of the ER process performed in BPMN, set out in Appendix B, has as a support tool the SIPOC diagram. The process representation starts with the EnMT defining the ER performance by the engineering ending with the approval by the Top Management and returns to EnMT to implement the objectives, targets and action plans. The execution of this process is arranged in the following modeling elements: (i) a pool representing the ER process; (ii) seven subdivisions (milestones) of the process steps described in Figure 7; (iii) five lanes representing the functional areas of Top Management, EnMT/energy manager, engineering, maintenance and production; (iv) ten gateways that define the paths that the flow should follow to the next step; (v) twenty-six activities to be performed; (vi) a start event, two end events, and a message end event. The activities that make up the ER process have already been described in section "Mapping and description of the Energy Review (ER) process".

\section{DISCUSSION}

The applicability of the methodology, based on the BPM cycle, is appropriate for EnMS in the industry, since the design and modeling allow to analyze the EnMS as a process 
for understanding the activities, assist decision making, automate processes, enable collaboration, allow alignment of the process with the strategy and support the changes and assist in the evaluation of the organizational potential to implement the EnMS.

The unfolding of the actions of the EnMS in processes, activities and tasks, according to the methodology proposed and still not considered in the studies and models presented in the scientific literature, provides opportunities for a better understanding of the activities, facilitates knowledge management, confirms that the activities carried out in a process add value, overcomes obstacles and functional barriers, creates greater security and knowledge about the roles and responsibilities of process actors, among other benefits. These elements and requirements approximate the dimensions of interoperability, placing it as an element associated to the good performance of processes in energy management.

\section{CONCLUSION}

This paper presents the partial results of a study under development. The EE approach, through the business process management to perform the EnMS in the EII and based on ISO 50001 (International Standard), allows to establish through the process design the actors, functional areas involved, roles, responsibilities, flow of activities and so on.

The ER process modeling allows designing a new process, describing requirements for automation, facilitating communication and discussion, evaluating standards and conformities, and simulating different situations. This chain will facilitate the internal coordination, transparency of the activities involved in the process and will aid in the decision-making of issues related to energy management. As already mentioned, these are elements associated with the concept of interoperability. The relationship between the performance of energy management from a process perspective and the fulfillment of interoperability requirements is an issue of interest in the evolution of the present research.

The design of the EnMS process highlighted aspects relevant to the energy intensive industries, such as: cogeneration, distributed generation, industrial processes, EMMES/MT\&R and submetering, appropriate instrumentation for energy maintenance, software and simulators, among others. All these aspects can be evaluated in future case studies. The research is currently restricted to the development of the ER process model. It is foreseen the mapping and modeling activities for the other suggested processes. In addition, there is still need for practical application in case studies to be conducted in the industry.

\section{REFERENCES}

1. Jaffe AB, Stavins RN. The energy-efficiency gap: what does it mean?. Energy Policy. 1994; 22: $804-810$.

2. Decanio SJ. The efficiency paradox: bureaucratic and organizational barriers to profitable energy-saving investments. Energy Policy. 1998; 26(5): 441-454.

3. Groot HLF, Verhoef ET, Nijkamp P. Energy Saving by firms: decision-making, barriers and policies. Energy Econ. 2001;23:717-740.

4. Associação Brasileira de Normas Técnicas. NBR ISO 50001:2011 - Energy Management Systems - Requirements with Guidance for Use. Rio de Janeiro, 2011.

5. Hoogervorst JAP. A framework for Enterprise Engineering. International Journal of Internet and Enterprise Management. 2009;7(1): 5-40.

6. Deschamps F, Lima EP, Costa SEG, Santos EAP, \& Aken EV. Development of Enterprise Engineering Guidelines for Enterprise Diagnosis and Design. In: Proceedings of the 2013 Industrial and Systems Engineering Research Conference; San Juan, Puerto Rico. 2013. p. 807816. 
7. Weske M. Business Process Management: Concepts, Languages, Architectures. SpringerVerlag Berlin. Heidelberg; 2007.

8. Galbraith JR. Designing Organizations: an executive briefing on strategy, structure and process. San Francisco: Jossey-Bass; 1995.

9. Daft RL. Theory and Projects of Organizations; 6th ed. Rio de Janeiro: LTC; 1999.

10. Cagno E. et al. A novel approach for barriers to industrial energy efficiency. Renew Sust Energ Rev, 2013;19: 290-308.

11. Thollander P, Ottosson M. An energy efficient Swedish pulp and paper industry - exploring barriers to and driving forces for cost-effective energy efficiency investments. Energy Eff. 2008;1(1):21-34.

12. Sorrell S. et al. Barriers to Energy Efficiency in Public and Private Organizations - final report. SPRU; 2000.

13. Weber L. Some reflections on barriers to the efficient use of energy. Energy Policy 1997; 10:833-835.

14. Aflaki S, Kleindorfer PR. Polvorinos VSM. Finding and Implementing Energy Efficiency Projects in Industrial Facilities. Prod Oper Manag. 2013; 22(3): 503-517.

15. Ates SA, Durakbasa NM. Evaluation of corporate energy management practices of energy intensive industries in Turkey. Energy. 2012;45(1):81-91.

16. Schulze M, Nehler H, Ottosson M, Thollander P. Energy management in industry - a systematic review of previous findings and an integrative conceptual framework. J Clean Prod. 2016;112:3692-3708.

17. Christoffersen B, Larsen A, Togeby M. Empirical analysis of energy management in Danish industry. J Clean Prod. 2006; 14(5):516-526.

18. Bunse K, Vodicka M, Schönsleben P, Brülhart M, Ernst F, 2011. Integrating energy efficiency performance in production management-gap analysis between industrial needs and scientific literature. J Clean Prod. 2011;19:667-679.

19. Vikhorev K, Greenough R, Brown N. An advanced energy management framework to promote energy awareness. J Clean Prod. 2013; 43.

20. Abpmp. Bpm Cbok V3.0 Guide to the Business Process Management Common Body of Knowledge. 2th ed. Brazil: Association of Business Process Management Professionals; 2014.

21. Capote G. BPM for all - A Comprehensive, Objective, and Insightful Overview of Business Process Management. Rio de Janeiro: Bookess, 2011.

22. Pidd M. Business Modeling, Decision Making Tools - Porto alegre: Bookman, 1998.

23. Bpmi/Omg. Business Process Modeling Notation (BPMN) Information; c2016 [cited 2017 Jul 02]. Available from: http://www.bpmn.org.

24. Bizagi. Bizagi Process Modeler. 2010.

25. United States Environmental Protection. Teaming Up to Save Energy. Washington, D.C.: Climate Protection Division, Report 430-K-05-007; 2006.

26. National conservation and rational use of energy policy, Pub. L. No. 10.295 (October 17, 2001).

27. Efficiency Valuation Organization (EVO). International Measurement and Performance Verification Protocol. Toronto, 2005.

28. International Organization for Standardization. ISO 50015:2014-Energy management systems - Measurement and verification of energy performance of organizations - General principles and guidance. Switzerland, 2014. 
Appendix A: Macro Horizontal Flowchart of the Process of an Energy Management System in Industry

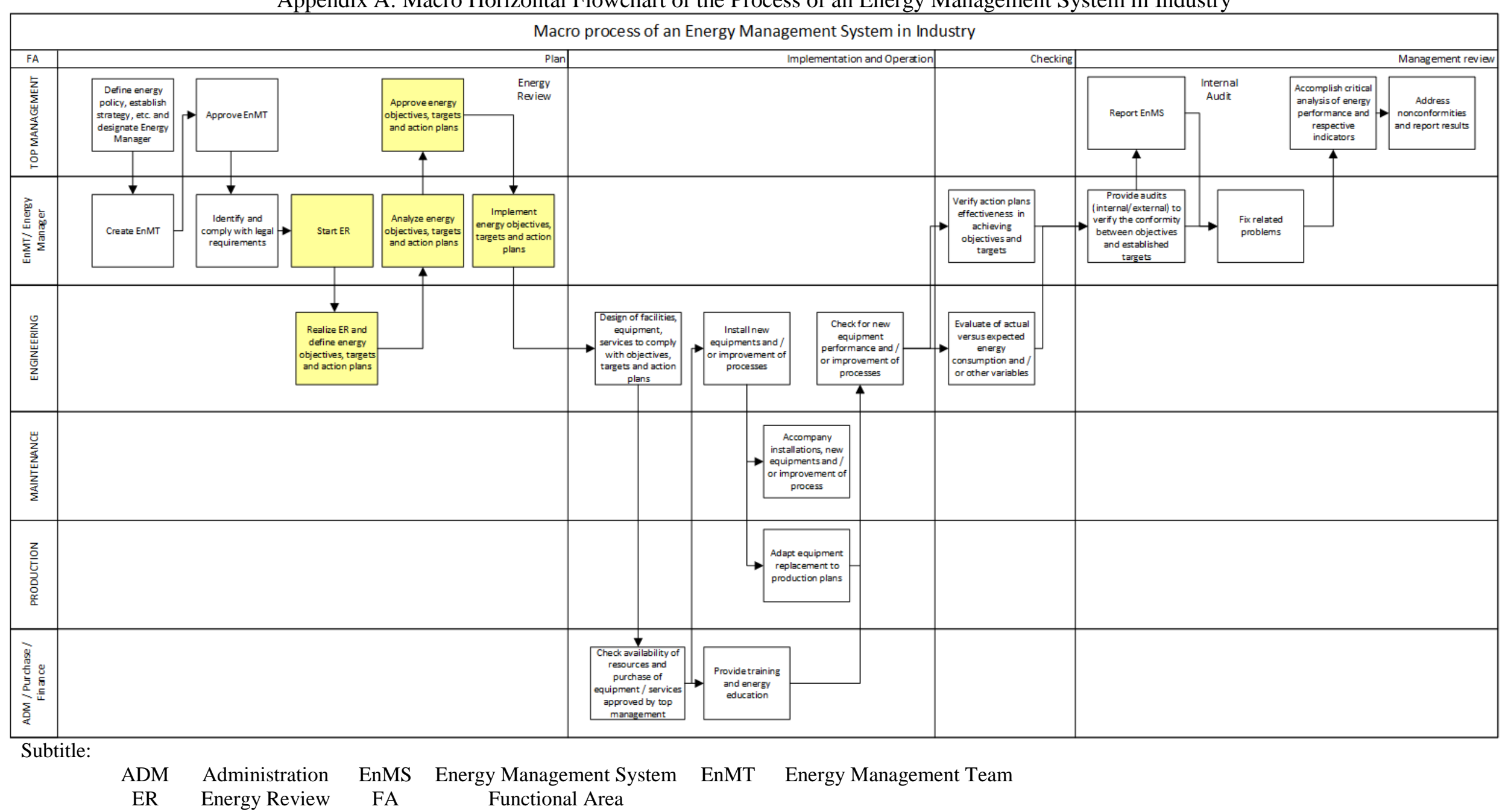

Figure 8: Macro horizontal flowchart of the process of an energy management system in industry.

Source: The author, 2017. 
Appendix B: Modeling of the Energy Review Process

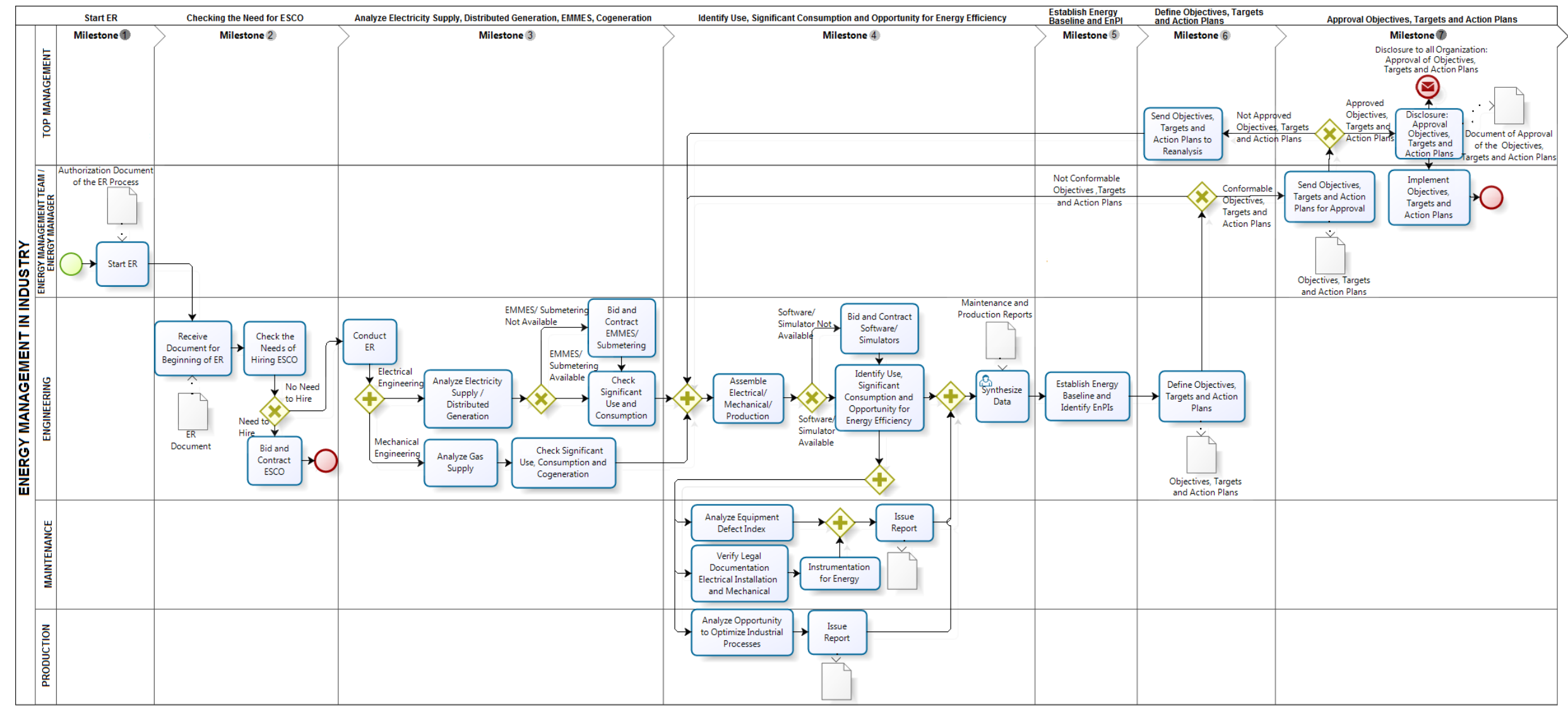

Subtitle:

$\begin{array}{ccc}\text { EMMES } & \text { Electronic Monitoring and Measurement Energy System } & \text { ER } \\ \text { EnPI } & \text { Energy Performance Indicator } & \text { ESCO }\end{array}$

Energy Review

ESCO Energy Saving Companies

Ps. the acronym ESCO represents ESCO itself and / or specialist.

Figure 9: Modeling of the energy revision process in BPMN notation.

Source: The author, 2017. 